\title{
Criticality Research in the Materials Community
}

\author{
M. L. BUSTAMANTE ${ }^{1}$ G. GAUSTAD, ${ }^{1,2}$ and M. GOE ${ }^{1}$ \\ 1.-Golisano Institute for Sustainability, Rochester Institute of Technology, Rochester, NY 14623, \\ USA. 2.—e-mail: gabrielle.gaustad@rit.edu
}

As materials scientists and engineers, the primary focus of our industry is on performance. Whether selecting from existing materials and processes or developing new alloys and processing techniques, it is first and foremost important to meet the functional requirements of any given application. Next, it is often most logical and practical to select the option which minimizes cost while maximizing performance. However, what role do other factors, such as life cycle environmental impacts and supply-chain security, play in this decision-making process? What role should they play, now and in the future? And what is our responsibility, as a community, in leading the way?

Historically, the aforementioned issues have been considered ancillary and were largely neglected in major materials design decisions. However, over the past 50 years, several events have forced these concerns into the spotlight. For example, in the 1970s, a small-scale uprising in Zaire (now the Congo) created a short-term supply shortage in cobalt as $40 \%$ of global production was mined in that geographic area. This caused massive spikes in the commodity price of cobalt, which resulted in speculation, government stockpiling, and massive disruption to firms in the semiconductor industry. ${ }^{1}$ Additionally, the introduction of the Environmental Protection Agency (EPA) and its various policies (Toxic Substances Act, Clean Air Act, Clean Water Act, etc.) changed the way many materials could be used. For example, in light of new evidence as to its extremely high toxicity, substitution of lead became a priority in the 1980 s for applications such as gasoline additives and paint pigments. However, because of the lack of substitutes in battery applications, lead use has increased overall. ${ }^{2}$

When considered together, these factors begin to form part of the larger picture that is materials criticality. Although it lacks a consistent definition

Gabrielle Gaustad is the guest editor for the Recycling and Environmental Technologies Committee, a joint committee of the TMS Extraction \& Processing and the Light Metals divisions, and coordinator of the topic Critical Materials: Strategies for Achieving Sustainability in this issue. throughout the literature, criticality is generally defined as a dynamic, multidimensional characteristic of materials, which describes the level of inherent vulnerability as well as the risk within their respective supply-chains. This special topic in JOM highlights some articles representing international, industrial, and academic perspectives on the complex and evolving issue of materials criticality. It is the hope that this issue will increase awareness and inspire further developments that help improve our collective understanding of criticality and its impact on the material science field. There will be a criticality plenary session at the upcoming TMS annual meeting in Orlando, Florida, and a future expanded special topic in the June issue of JOM (manuscript deadline of February 15, 2015).

The most basic type of criticality research focuses on concerns over physical abundance or scarcity. Concerns over material availability, especially for emerging technologies, are not new and over the last 70 years have sparked debates as well as national policies aimed at securing critical materials. ${ }^{3,4}$ For example, the most recent Department of Defense Strategic and Critical Materials report per the Strategic and Critical Materials Stockpiling Act uses material consumption, production, and projected future demand to determine the severity of material criticality. Similarly, in previous literature $^{1,5-9}$ the material availability is determined primarily by physical scarcity. Scarcity research calculates static metrics, such as depletion time (a measure of how long known reserves will last, given current levels of extraction); although it is informative and useful, it can provide only limited resolution of the real and complex issues at hand. In reality, criticality is a dynamic characteristic; however, dynamic approaches are challenging and therefore lacking in the literature. However, a few studies have been published in recent years employing dynamic material flow analysis ${ }^{1,10}$ and agent-based modeling. ${ }^{11}$

Expanding on physical scarcity is an approach first introduced by the National Research Council's 
2008 report titled, "Minerals, Critical Minerals, and the U.S. Economy," where two dimensions of criticality are defined: (I) supply risk (of which scarcity is a factor) and (II) impact of supply restriction (of which demand factors such as substitutability is a factor). ${ }^{12}$ Since its introduction, this two-dimensional approach has been applied by government agencies (e.g., Department of Energy, ${ }^{13}$ United Nations Environmental Programme, ${ }^{14}$ and European Commission) ${ }^{15,16}$ and industry (e.g., General Electric $^{17}$ ) to analyze criticality at various scales (local, corporate, national, and international) for various economic sectors (energy, electronics, etc.) and for various timescales (short-term, mid-term, long-term). However, the most common sector of focus in these and other published studies is, by far, the energy sector because of interests in changing energy mix and potential sustainability trade-offs represented by clean technologies based on scarce, risky materials.

More recently, criticality research has begun considering the role of environmental factors in supply-chain security, as alluded to in the original NRC report. ${ }^{12}$ The Yale Critical Materials Group has identified some indicators in this category such as human health and ecosystem damages. ${ }^{18}$ Since then, other researchers, such as Goe and Gaustad, have stepped in to apply and expand upon this three-dimensional approach to characterizing criticality. ${ }^{19}$ The Yale Group currently has several recent and forthcoming publications of this type, focusing on different groups of materials from their own application of the three-dimensional model, which is now composed of more than two dozen indicators. $^{20-24}$ The key results of these studies are summarized in one of this issue's own articles by Graedel and Nuss. ${ }^{25}$ In this article, the authors compile the findings of a broad elemental study on criticality into useful indicators and guidelines for product and process designers to apply in their decision-making processes. ${ }^{26}$

The research summarized thus far only represents one family of criticality research: criticality characterization. Another important focal point is on criticality mitigation. Research in this space investigates possible strategies for reducing risk in the supply chain, such as finding substitutes for the critical material. An example of this type of research can be found in this issue's featured article from GE Aviation, focusing on the evaluation of a substitute for high-purity rare-earth oxides in the synthesis of disilicate, ceramic matrix composites, used for the protection of important engine components. ${ }^{27}$ Other examples look at the role of recycling, reduction of material utilization, and improvement of yield in mitigating supply risk. ${ }^{10,28,29}$ There is tremendous value and opportunity in future research of mitigation strategies, and it requires the technical expertise of the materials community. ${ }^{30}$

By staying up to date on criticality research and emerging issues, we of the materials community can make better decisions in the future which could ultimately improve the sustainability of various products and supply chains. We can do so by choosing or developing better substitutes for critical materials, by finding ways to further reduce the amount of critical material required, and by developing novel recycling methods and higher efficiency, greener extraction methods. Therefore, to answer the questions posed at the beginning of this introduction, it is paramount that we as members of the materials community recognize the amount of leverage we have to address future issues of materials criticality. The broad compilation of research provided in this JOM special topic could serve as a useful starting point for those new to criticality or as fuel for further research for specialists.

\section{REFERENCES}

1. E. Alonso, A.M. Sherman, T.J. Wallington, M.P. Everson, F.R. Field, R. Roth, and R.E. Kirchain, Environ. Sci. Technol. 46, 3406 (2012).

2. T.D. Kelly and G.R. Matos, eds., Historical Statistics for Mineral and Material Commodities in the United States: Lead Statistics (Washington, DC: USGS, 2005), http:// minerals.usgs.gov/minerals/pubs/mcs/2005/mcs2005.pdf.

3. J.A. McClure, Idaho L. Rev. 19, 417 (1983).

4. G.K. Jones, BC Environ. Aff. L. Rev. 15, 217 (1987).

5. V. Fthenakis, Renew. Sustain. Energy Rev. 13, 2746 (2009).

6. I. Kapilevich and A. Skumanich Proceeding of the 34th IEEE Conference (Piscataway, NJ, IEEE, 2009), pp. 002055002060.

7. K. Zweibel, Science 328, 699 (2010).

8. C. Candelise, J.F. Speirs, and R.J.K. Gross, Renew. Sustain. Energy Rev. 15, 4972 (2011).

9. Y. Houari, J. Speirs, C. Candelise, and R. Gross, Prog. Photovolt. 22, 129 (2014).

10. M.L. Bustamante and G. Gaustad, Appl. Energy 123, 397 (2014).

11. C. Knoeri, P.A. Wäger, A. Stamp, H.-J. Althaus, and M. Weil, Sci. Total Environ. 461, 808 (2013).

12. National Research Council, Minerals, Critical Minerals, and the U.S. Economy (Washington, DC: National Academies Press, 2008).

13. D. Bauer, D. Diamond, J. Li, D. Sandalow, P. Telleen, and B. Wanner, Critical Materials Strategy (Washington, DC: U.S. Department of Energy, 2010).

14. M. Buchert, D. Schüler, and D. Bleher, Critical metals for future sustainable technologies and their recycling potential (Nairobi: United Nations Environment Program DTIE, 2009).

15. European Commission, Critical Raw Materials for the EU (Brussels, Belgium: European Commission, 2010), http://ec. europa.eu/enterprise/policies/raw-materials/files/docs/report-b_ en.pdf.

16. R. Moss, E. Tzimas, H. Kara, P. Willis, and J. Kooroshy, JRC Scientific and Strategic Reports: Critical Metals in Strategic Energy Technologies: Assessing Rare Metals as Supply-Chain Bottlenecks in Low-Carbon Energy Technologies (Brussels: European Commission Joint Research Centre Institute for Energy and Transport, 2011).

17. D. Konitzer, S. Duclos, and T. Rockstroh, MRS Bull. 37, 383 (2012).

18. T. Graedel, R. Barr, C. Chandler, T. Chase, J. Choi, L. Christoffersen, E. Friedlander, C. Henly, C. Jun, and N.T. Nassar, Environ. Sci. Technol. 46, 1063 (2012).

19. M. Goe and G. Gaustad, Appl. Energy 123, 387 (2014).

20. N.T. Nassar, R. Barr, M. Browning, Z. Diao, E. Friedlander, E. Harper, C. Henly, G. Kavlak, S. Kwatra, and C. Jun, Environ. Sci. Technol. 46, 1071 (2012).

21. P. Nuss, E. Harper, N. Nassar, B.K. Reck, and T. Graedel, Environ. Sci. Technol. 48, 4171 (2014). 
22. E. Harper, Z. Diao, S. Panousi, P. Nuss, M. Eckelman, and T. Graedel, unpublished work (2014).

23. E. Harper, G. Kavlak, L. Burmeister, M. Eckelman, S. Erbis, V. Espinoza, P. Nuss, and T. Graedel, unpublished work (2014).

24. S. Panousi, E. Harper, P. Nuss, M. Eckelman, A. Hakimian, and T. Graedel, J. Indus. Ecol., in press.

25. T.E. Graedel and P. Nuss, JOM 66 (2014). doi:10.1007/ s11837-014-1188-4.

26. T.E. Graedel and P. Nuss, Mater. Crit., unpublished work (2014).
27. A.Y. Ku, C. Dosch, T.R. Grossman, J.L. Herzog, A.F. Maricocchi, D. Polli, and D.M. Lipkin, JOM 66 (2014).

28. X. Du and T. Graedel, Environ. Sci. Technol. 45, 4096 (2011).

29. M. Marwede and A. Reller, Resour. Conserv. Recycl. 69, 35 (2012).

30. National Research Council, The Role of the Chemical Sciences in Finding Alternatives to Critical Resources: A Workshop Summary (Washington, DC: National Academies Press, 2012). 